Document downloaded from:

http://hdl.handle.net/10251/67016

This paper must be cited as:

Serra, M.; García Baldoví, H.; Alvaro Rodríguez, MM.; García Gómez, H. (2015). Doped Framework Iron Hydroxyl Phosphate as Photocatalyst for Hydrogen Production from Water/Methanol Mixtures. European Journal of Inorganic Chemistry. 2015(25):4237-4243. doi:10.1002/ejic.201500629.

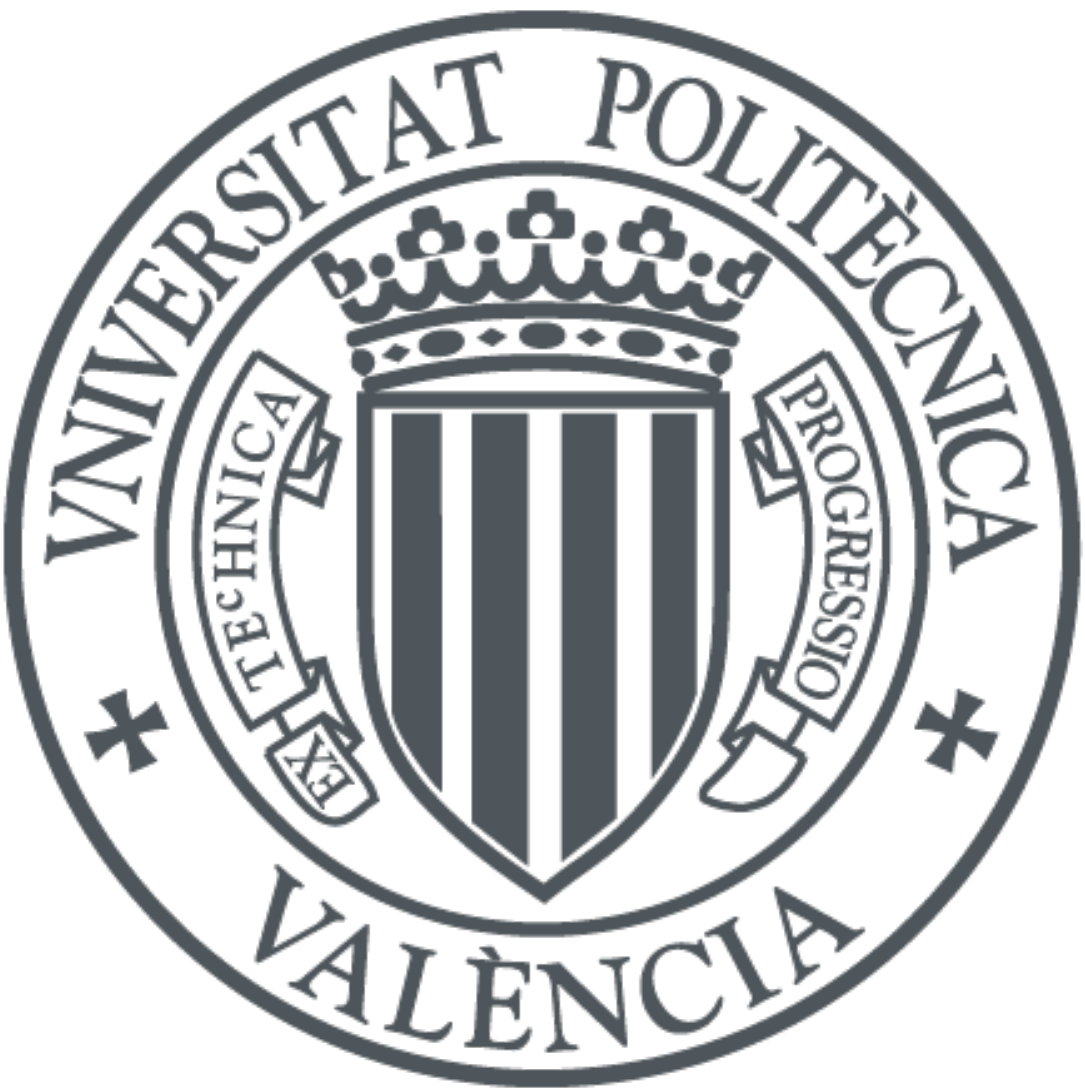

The final publication is available at

https://dx.doi.org/10.1002/ejic.201500629

Copyright Wiley

Additional Information 


\title{
Doped framework iron hydroxyl phosphate as novel photocatalyst for hydrogen production from water-methanol mixtures
}

\author{
Marco Serra, Herme G. Baldovi, Mercedes Alvaro and Hermenegildo Garcia*
}

Dedication ((optional))

\begin{abstract}
In the search for novel photocatalysts for hydrogen production and having as a recent precedent $\alpha-\mathrm{Fe}_{2} \mathrm{O}_{3}$ as photoelectrocatalyst, preparation, properties as semiconductor and photocatalytic activity of metal doped ( 0.1 to $5 \mathrm{wt} \%$ loading) iron hydroxyl phosphate $(\mathrm{FeP})$ is reported. X-ray diffraction of FeP samples submitted to extended photocatalytic irradiations shows the stability of this framework phosphate under photocatalytic condition. Doping increases the photocatalytic efficiency of FeP for all dopants, being an optimal doping level between 0.1 and $1 \%$. Under optimized conditions $(\mathrm{Cr}$ at $1 \%$ doping level), the photocatalytic activity of $\mathrm{FeP}$ reaches a hydrogen production rate of $35.82 \mu \mathrm{mol} / \mathrm{g}_{\mathrm{Fe}} \mathrm{h}$ in the absence of platinum as cocatalyst. The conduction flat band potential was estimated by photocurrent measurements or impedance spectroscopy as $0.1 \mathrm{eV}$ vs. NHE and the charge carrier density $2.6 \times 10^{20}$ carriers $/ \mathrm{cm}^{3}$. Transient absorption spectroscopy has allowed us the detection transient species decaying in the microsecond timescale characterized by a broad band spanning from 300 to $750 \mathrm{~nm}$. This transient was attributed to the charge separated state. These results are promising to develop novel photocatalytic materials based on metal framework phosphate
\end{abstract}

\section{Introduction}

Photocatalysis is gaining importance because in addition to degradation of pollutants in gas o liquid phase, it could also be an alternative for solar light conversion. ${ }^{[1-5]}$ Due to the shortage in fossil fuels, a considerable effort is focused on the development of renewable energies. Sunlight reaching the Earth surface is one of the primary energy resources that provides enough energy to cover the energy demand in the future. ${ }^{[6-9]}$ However, due to the low power density of solar light, cycles of day and night, as well as the weather dependence, solar light as renewable energy has to be combined with energy vectors that accumulate and concentrates the solar energy. One possible strategy is the generation of hydrogen from water or the production of other solar fuels, based on solar light photocatalysis. ${ }^{\text {7, 10-16] }}$

In photocatalysis the energy of the light is converted by a solid into chemical energy. ${ }^{[17-22]}$ In typical photocatalysts absorption of a photon leads to the generation of charge separated state. The most widely used photocatalyst, also for the production of hydrogen and solar fuels, is titanium dioxide. ${ }^{[17,19,21]}$ This solid presents several advantages including availability, lack of toxicity and high photocatalytic efficiency under UV light irradiation. However, $\mathrm{TiO}_{2}$ presents severe limitations that have proven to be difficult to overcome.

The most important limitations of $\mathrm{TiO}_{2}$ as photocatalyst are its wide bandgap and the occurrence of charge recombination in a large extent. For these reasons, the performance under sunlight illumination of $\mathrm{TiO}_{2}$ as photocatalyst is far from optimal and there is a continuous interest in developing new photocatalysts. Of relevance for the present work is also the finding of the photoelectrochemical activity for hydrogen generation from water of $\alpha-\mathrm{Fe}_{2} \mathrm{O}_{3}$ powders. ${ }^{[23-28]}$ One of the main advantages of iron oxide is its lack of toxicity and its large abundance. However iron oxide presents as major drawback in photocatalysis its low reduction potential of conduction band electrons $(-0.4 \mathrm{eV}$ vs $\mathrm{NHE}\left[{ }^{[29]}\right]$ ) that makes water reduction of $\mathrm{H}_{2}$ thermodynamically uphill. This makes necessary to submit the $\alpha-\mathrm{Fe}_{2} \mathrm{O}_{3}$ photoanode to about $1 \mathrm{~V}$ bias potential. In addition, $\alpha-\mathrm{Fe}_{2} \mathrm{O}_{3}$ tends to undergo photocorrosion, leading to the dissolution of $\mathrm{Fe}^{3+}$ during the photocatalytic reaction. In this context it would be important to evaluate other water-insoluble iron compounds that could perform as photocatalyst.

Considering the interest in developing new photocatalysts, in the present manuscript we report the photocatalytic activity of open framework iron hydroxyl phosphate $(\mathrm{FeP})$ for $\mathrm{H}_{2}$ generation from $\mathrm{CH}_{3} \mathrm{OH} / \mathrm{H}_{2} \mathrm{O}$ mixture that is comparable to that of commercial $\mathrm{TiO}_{2} \mathrm{P} 25$ under simulated sunlight irradiation. Open framework phosphates are those materials that in contrast to bulk phosphates only contain Metal-O-P linkages leaving interstitial channels in which a protonated amine remains entraped compensating the net negative charge of the lattice. As it will be showns below, compared to $\mathrm{TiO}_{2}$, the use of $\mathrm{FeP}$ has the additional advantage of an easy doping. We have found that the photocatalytic activity of $\mathrm{FeP}$ depends on the nature and percentage of dopant. The proprieties as semiconductor were characterized by measuring conduction band potential, band gap, density of charge carriers and by transient absorption spectroscopy characterization of the charge separated state.

Since phosphates can be prepared by hydrothermal crystallization in the presence of a large variety of metals in a range of concentrations resulting in doping, our finding can open new directions in the search for novel efficient photocatalysts. In the literature, there is only one precedent on the use of $\mathrm{Fe}(\mathrm{OH}) \mathrm{PO}_{4}$ as photocatalyst for the degradation of methylene blue under visible light irradiation [30], but up to now the photocatalytic activity for hydrogen generation remains unexplored. In addition, we also show the effect of metal doping to increase the efficiency of FeP as photocatalyst.

\section{Results and Discussion}

In the initial part of our study open framework FeP was synthetized by hydrothermal crystallization at $150{ }^{\circ} \mathrm{C}$ of an aqueous solution of iron chloride, ethylenediamine as base and templating agent, and phosphoric acid as source of phosphate, following reported procedure. ${ }^{[31}$ Besides FeP having a single 
metal, the synthesis of a wide range of $\mathrm{FeP}$ having in various minor proportions $\mathrm{Cr}, \mathrm{Mn}$, or Co from 0.25 to $5 \mathrm{wt} \%$ was also performed. The possibility of doping $\mathrm{FeP}$ has now been considered in the literature so far. Specifically, we prepared three families of materials, based on $\mathrm{FeP}$, depending on nature of the dopant element. The set of materials and the main analytical and characterization data are summarized in Table 1.

Table1. Code, composition and photocatalytic data of the FeP samples under study.

\begin{tabular}{|c|c|c|c|c|}
\hline \multirow[t]{2}{*}{ Code ${ }^{[a]}$} & Metal & Comostion (wt\%) & $\begin{array}{l}\mathrm{H}_{2} \\
\text { Production }\end{array}$ & $\underset{\text { (b) }}{\mathrm{H}_{2} \text { Productor }}$ \\
\hline & Dopant & $\mathrm{Fe}$ & $(\mu \mathrm{mol})$ & \\
\hline \multicolumn{2}{|l|}{$\mathrm{FeP}[\mathrm{c}]$} & 100 & $0.36 \pm 0.05$ & $15 \pm 2$ \\
\hline$(0.25 \mathrm{Cr}) \mathrm{FeP}$ & Cr:0.28 & 99.7 & 0.54 & 22 \\
\hline$(0.5 \mathrm{Cr}) \mathrm{FeP}[\mathrm{cc}$ & Cr:0.48 & 99.5 & $0.83 \pm 0.06$ & $34 \pm 5$ \\
\hline$(1 \mathrm{Cr}) \mathrm{FeP}[\mathrm{c}]$ & Cr:90 & 99.1 & $0.87 \pm 0.06$ & $36 \pm 5$ \\
\hline$(2 \mathrm{Cr}) \mathrm{FeP}$ & Cr:2.30 & 97.7 & 0.64 & 26. \\
\hline$(5 \mathrm{Cr}) \mathrm{FeP}$ & Cr:4.0 & 96.0 & 0.63 & 26 \\
\hline$(0.25 \mathrm{Mn}) \mathrm{FeP}$ & Mn:0.20 & 99.8 & 0.51 & 21 \\
\hline$(0.5 \mathrm{Mn}) \mathrm{FeP}$ & Mn:0.35 & 99.65 & 0.46 & 19 \\
\hline$(1 \mathrm{Mn}) \mathrm{FeP}$ & $\mathrm{Mn}: 1.0$ & 99.0 & 0.42 & 17 \\
\hline$(2 \mathrm{Mn}) \mathrm{FeP}$ & Mn:1.20 & 98.8 & 0.37 & 15 \\
\hline$(5 \mathrm{Mn}) \mathrm{FeP}$ & $\mathrm{Mn}: 3.3$ & 96.7 & 0.36 & 15 \\
\hline$(0.25 \mathrm{Co}) \mathrm{FeP}$ & Co:0.13 & 99.87 & 0.53 & 22 \\
\hline (0.5Co) FeP & Co:0.27 & 99.73 & 0.54 & 22 \\
\hline (1Co) FeP & Co:0.42 & 99.58 & 0.6 & 25 \\
\hline (2Co) FeP & Co:0.80 & 99.2 & 0.55 & 23 \\
\hline (5Co)FeP & Co:2.1 & 97.9 & 0.38 & 16 \\
\hline $\begin{array}{l}\text { [a] The emp } \\
\times \mathrm{x}_{\mathrm{x}}\left(\mathrm{HPO}_{4}\right)_{2}(\mathrm{O} / \\
{\left[{ }^{[b]} \mathrm{H}_{2} \text { productio }\right.} \\
{ }^{[c]} \text { Average of } \mathrm{fc}\end{array}$ & $\begin{array}{l}\text { cal formu } \\
\mathrm{H}_{2} \mathrm{O} \text { with } \\
\text { after } 6 \mathrm{~h} \text { irn } \\
\text { Ir independ }\end{array}$ & $\begin{array}{l}\text { of } \mathrm{FeP} \text { photoc } \\
\mathrm{A}=\mathrm{Cr}, \mathrm{Mn} \text { or } \mathrm{Co} \text {. } \\
\text { diation with solar sin } \\
\text { nt measurements. }\end{array}$ & $\begin{array}{l}\text { alyst is } \\
\text { ator. }\end{array}$ & ${ }_{10)} \quad \mathrm{Fe}_{(1-}$ \\
\hline $\begin{array}{l}\text { Those samp } \\
\text { that has bee } \\
\text { framework in } \\
\text { XRD pattern } \\
\text { for these ma }\end{array}$ & $\begin{array}{l}\text { es based } \\
\text { previous } \\
\text { in hydrox } \\
\text { for som } \\
\text { erials as }\end{array}$ & $\begin{array}{l}\text { on FeP exhibit a } \\
\text { y reported for th } \\
\text { I phosphate }{ }^{[31]} \text {. } \\
\text { of FeP samples } \\
\text { ported in the lite }\end{array}$ & $\begin{array}{l}\text { K-ray diffracti } \\
\text { one-dimensic } \\
\text { gure } 1 \text { show } \\
\text { as well as the } \\
\text { ature }{ }^{[31]},{ }^{[32]} \text {. }\end{array}$ & $\begin{array}{l}\text { on pattern } \\
\text { onal, open } \\
\text { s selected } \\
\text { e structure }\end{array}$ \\
\hline
\end{tabular}

Figure 1. (A) Building units of $\mathrm{FeP}$, view along $\mathrm{b}$ axis. Red atoms correspond to iron, green to phosphor and blue to oxygen. Hydrogen atoms, ethylenediamine and water molecules are omitted for clarity. The model of the Fe-O-P(O)-O chains was obtained using the Mercury program for the structure file ${ }^{[31]}$, ${ }^{[32]}$. (B) XRD pattern of the metal-doped samples. (a) FeP, (b) $(0.25 \mathrm{Cr}) \mathrm{FeP}$, (c) $(0.5 \mathrm{Cr}) \mathrm{FeP}$, (d) (1 Cr) FeP, (e) (2 Cr) FeP, (f) (5 Cr) FeP. For the XRD of the other samples see supporting information.
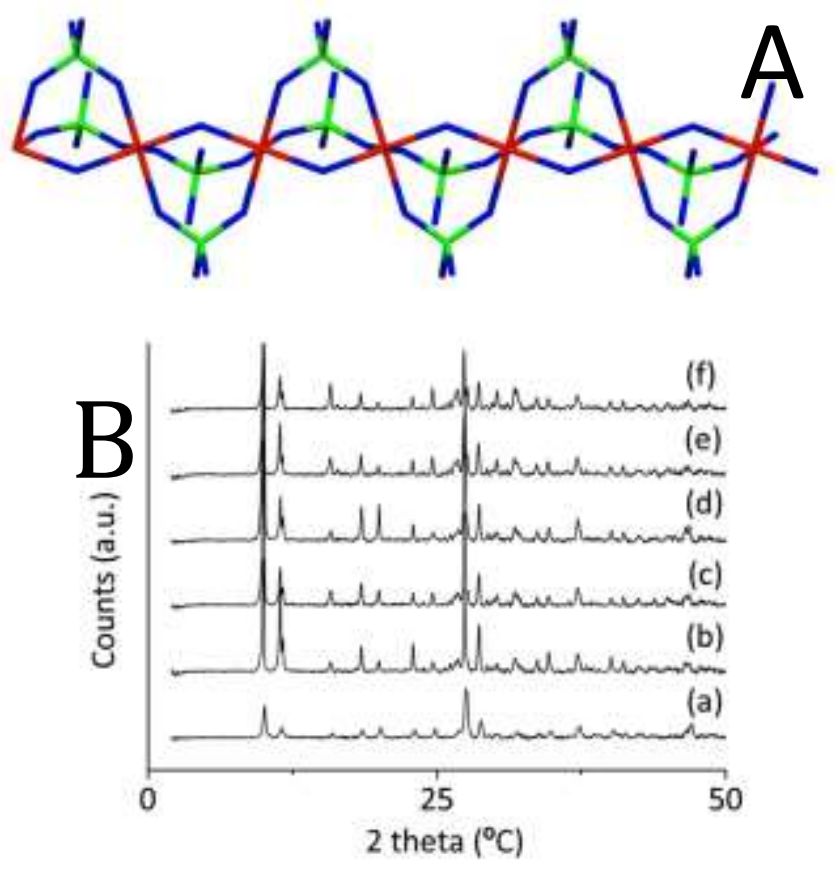

Neteworthy is the fact the crystallinity of FeP is maintained with some minor variations in the peak intensity in the presence of the dopant elements. The almost coincident cationic radii of $\mathrm{Fe}$ and $\mathrm{Cr}, \mathrm{Mn}$ or $\mathrm{Co}$ as well as their similar charge density allow their incorporation in a few percents in FeP structure without noticeable variation of the XRD. The crystal structure of FeP is constituted by chains of octahedra having one $\mathrm{Fe}^{3+}$ ion at the centre sharing two corners in trans position with $\mathrm{OH}$ groups. Phosphates anions define tetrahedra around $\mathrm{P}^{5+}$ ions connected by two oxygen atoms to two different octahedra and having in another corner one $\mathrm{OH}$ group. Ethylendiamine is present in diprotonated form occupying the interstitial space among the ctrains of octahedra interacting by strong electrostatic forces and by hydrogen bonds.

The morphology of FeP particles was determined by microscopy. The large size of some of the particles allows in this case the use of optical microscopy. Figure 2 presents representative images for FeP showing that the material is constituted by a broad distribution of crystals with long aspect ratio. Some of the particles were as long as at $100 \mu \mathrm{m}$, but some others were about $1 \mu \mathrm{m}$ length. These sub-millimetric crystals are formed by aggregation of much smaller sheets. Scanning electron microscopy reveals in better detail that the crystals are in reality aggregates of multitude of flakes with thickness about $0.5 \mu \mathrm{m}$ and length typically larger than $20 \mu \mathrm{m}$ (see also Figure 2B).

Of relevance with regard to the photocatalytic activity is the optical absorption spectra of the FeP samples that were very similar regardless the nature of the dopant and its percentage in the range from 0.25 to $5 \mathrm{wt} \%$ (Figure 3 ). All the samples exhibited two relative absorption maxima at 380 and $420 \mathrm{~nm}$ that can be attributed to $\mathrm{d}-\mathrm{d}$ transition of $\mathrm{Fe}^{3+}$ ions. These minor peaks are accompanied by an intense absorption band at 280 $\mathrm{nm}$ attributable to the ligand-to-metal O-Fe charge transfer band. 
Figure 2. A) SEM image recorded for FeP. B) Optical microscopy image at different magnification showing the large crystals present in FeP.
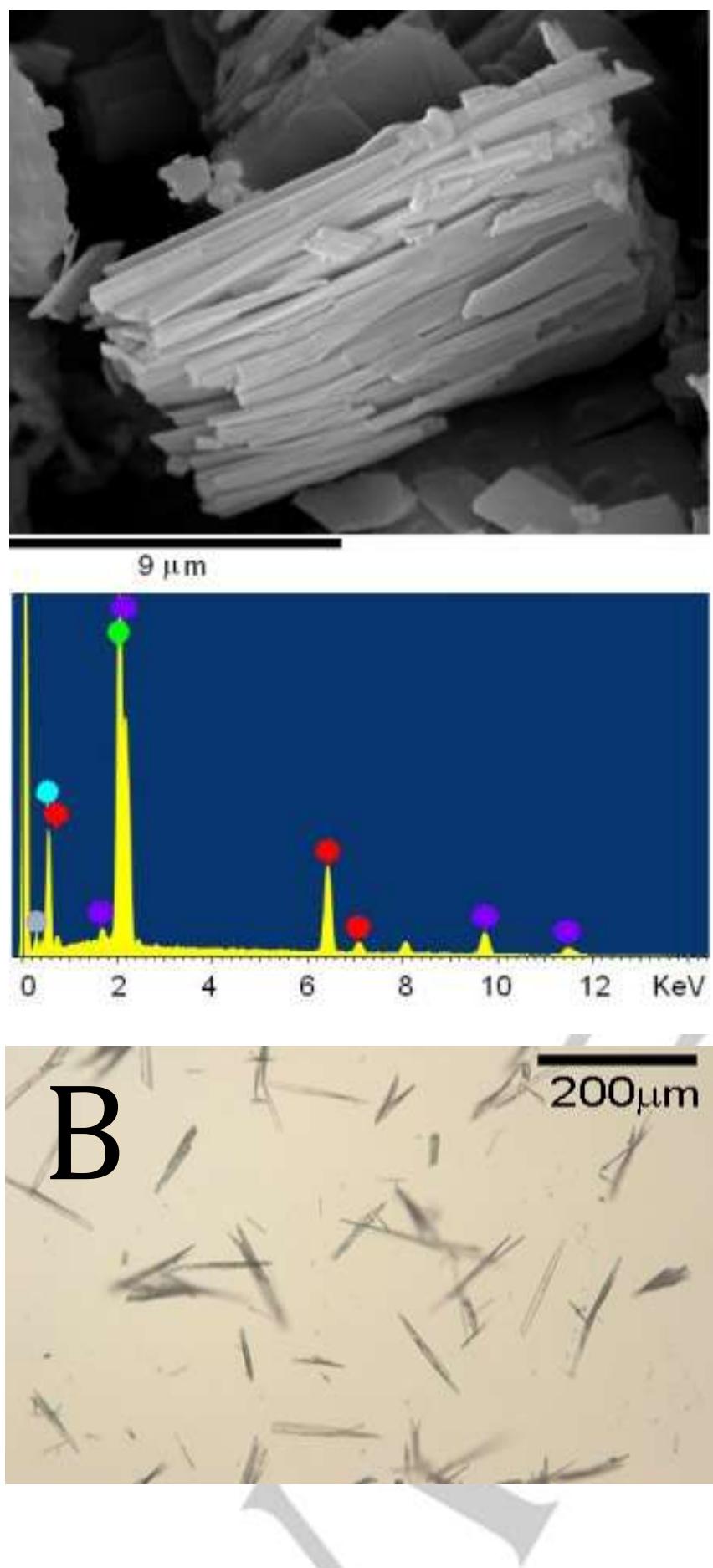

All the FeP samples under study exhibited photocatalytic activity for $\mathrm{H}_{2}$ generation under simulated solar light irradiation in $\mathrm{H}_{2} \mathrm{O} / \mathrm{CH}_{3} \mathrm{OH}$ mixture. No hydrogen evolution was obserbved for $\mathrm{FeP}$ in the absence of $\mathrm{CH}_{3} \mathrm{OH}$ under the same condtiions. Figure 4 shows the temporal profile of hydrogen evolution for the undoped FeP sample. The sample exhibits an induction period of about $1 \mathrm{~h}$ in which $\mathrm{H}_{2}$ does not evolve.
Figure 3. Diffuse reflectance UV-Vis absorption spectra (plotted as the Kubelka-Munk function of the remittance $(R)$ ) of the metal-doped FeP. For the UV-Vis spectra of the other doped FeP see supporting information. (a) FeP, (b) $(0.25 \mathrm{Cr}) \mathrm{FeP}$, (c) $(0.5 \mathrm{Cr}) \mathrm{FeP}$, (d) (1 Cr) FeP, (e) (2 Cr) FeP, (f) (5 Cr) FeP.

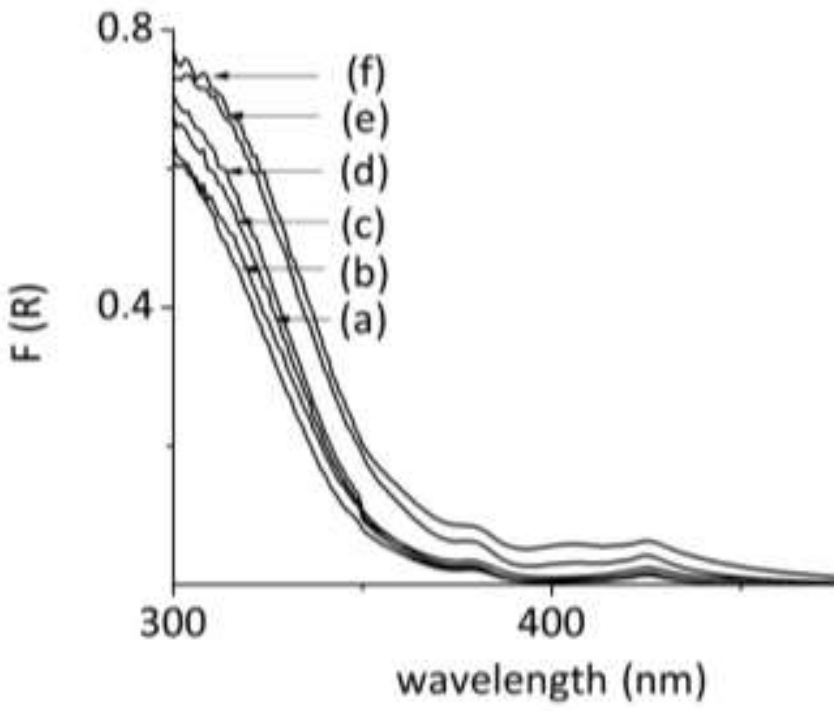

This induction period could be related to possible modifications in the oxidation state of $\mathrm{Fe}^{3+}$ in $\mathrm{FeP}$ or to the adsorption of hydrogen onto the solid before being detectable in the gas phase. Independently it was measured that $\mathrm{H}_{2}$ adsorption on $\mathrm{FeP}$ at room temperature was negligible. It is important to mention that this $\mathrm{H}_{2}$ production corresponds to a photocatalyst that does not contain any noble metal such as Pt as cocatalyst.

Figure 4. Photocatalytic hydrogen production from water-methanol mixtures using FeP as photocatalyst under simulated sunlight irradiation Vertical bar represents the relative error oft he measurements. Reaction conditions: Water-methanol (1:1) mixtures $25 \mathrm{~mL}$, catalyst concentration $1 \mathrm{~g} \times \mathrm{L}^{-1}$.

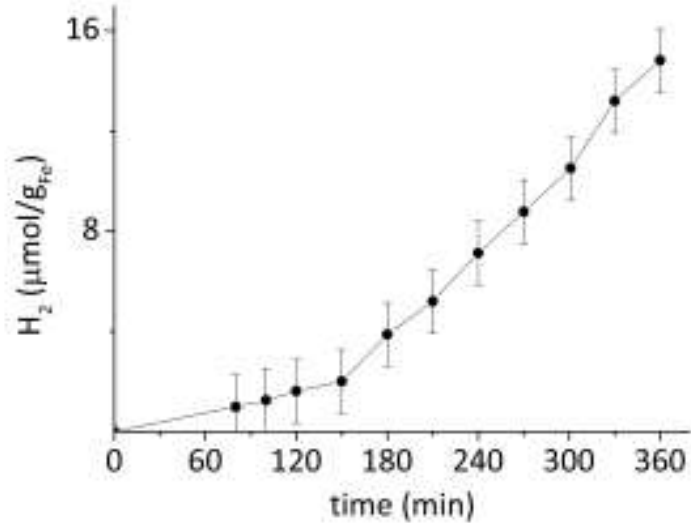

Irradiation with monochromatic light at $300\left(0.09 \mathrm{~mW} / \mathrm{m}^{2}\right)$ and $420 \mathrm{~nm}\left(5.8 \mathrm{~mW} / \mathrm{m}^{2}\right)$ leads to a hydrogen generation of 0.54 $\mu \mathrm{mol}$ and $0.58 \mu \mathrm{mols}$ in $6 \mathrm{~h}$. The fact that higher light power at $420 \mathrm{~nm}$ results in similar hydrogen generation as irradiation at $300 \mathrm{~nm}$ is probably a reflection of the much higher absorption at $300 \mathrm{~nm}$ of FeP (Figure 3). 
It should be commented that the $\mathrm{H}_{2}$ production of a P25 $\mathrm{TiO}_{2}$ sample under the same conditions as those shown in Figure 4 were $2.4 \mu \mathrm{mol}$ of $\mathrm{H}_{2}$ at $6 \mathrm{~h}\left(96 \mu \mathrm{mol}^{\circ} \mathrm{g}^{-1}\right)$ corresponding to about 6 times higher than that measured for FeP. It should be, however, commented that this comparison is based on the same photocatalyst weight and it does not really reflect intrinsic photocatalytic activity that are comparable anyway.

Concerning stability, chemical analysis of the solution after $6 \mathrm{~h}$ irradiation and removal of the solid catalyst shows an iron content below $10 \mathrm{ppb}$, indicating that the possible amount of $\mathrm{Fe}^{3+}$ leached from the photocatalyst has to be below $0.005 \%$ of the initial $\mathrm{Fe}^{3+}$ content.

This analytical data showing negligible $\mathrm{Fe}^{3+}$ leaching together with the lack of apparent change in the XRD pattern of the FeP samples after prolonged irradiation indicate the stability of $\mathrm{FeP}$ as photocatalyst. The results shown in Figure 4 have to be considered in the context of the lack of hydrogen production in the absence of bias potential of $\alpha-\mathrm{Fe}_{2} \mathrm{O}_{3}{ }^{[26]}$ and the low photostability of this oxide resulting in leaching $\mathrm{Fe}^{3+}$ to the solution and dissolution of the solid. ${ }^{[28]}$

The influence of doping on the photocatalytic activity for hydrogen generation is presented in Figure 5 . As can be see there for the three sets of samples the activity for hydrogen production is optimal when the dopant loading is between 0.1 and $1 \mathrm{wt} \%$, lower or higher loadings resulting in a decrease in the photocatalytic activity. Also the nature of the dopant element has an influence, chromium being the dopant metal for which the photocatalytic activity is the highest. According to the data shown in Figure 5 the amount of hydrogen can be increased by a factor 2.5 by incorporating in the composition chromium in a percentage about $1 \%$.

Figure 5. Hydrogen production from water-methanol mixtures at $6 \mathrm{~h}$ irradiation using doped FeP as photocatalysts under simulated sunlight irradiation. Reaction conditions: water-methanol mixtures (1:1) $25 \mathrm{~mL}$, catalyst

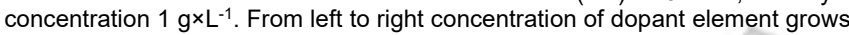
from: $0,0.25,0.5,1,2$ and $5 \%$

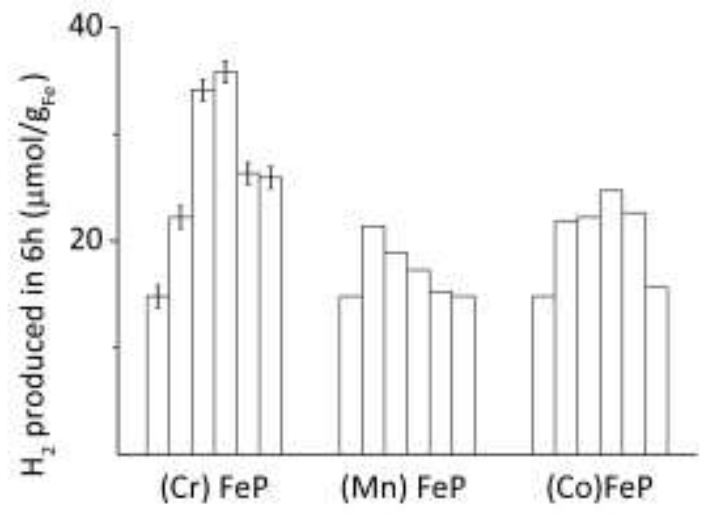

In analogy with $\mathrm{TiO}_{2}$, we propose that in the present case metal doping should operate by increasing the efficiency of charge separation. It is known that upon light absorption and generation of electrons in the conduction band and holes in the valence band, ultra fast charge recombination is the main deactivation pathway, limiting the efficiency of the photocatalytic reactions. ${ }^{[17]}$ Doping can introduce in the intra bandgap space additional states that can act as traps of electrons or holes, promoting charge separation and/or increasing the lifetime of the charge separated estate. Scheme 1 summarizes our proposal to explain the influence of doping and the more efficient hydrogen generation of doped semiconductors. The fact that there is an optimal doping level suggests that the positive effect of the dopant increasing the efficiency of charge separation by providing intra bandgap trapping sites is compensated by an increase in charge recombination efficiency caused at higher dopant concentrations. ${ }^{[21]}$

Scheme 1. Proposal for the influence of metal doping on the charge separation and hydrogen production of doped FeP. VB: valence band $\mathrm{CB}$ : conduction band. The dash line below $\mathrm{CB}$ correspond to the interband gap state introduced by the dopant element. (a) Charge separation; (b) Migration of conduction band electrons to the dopant level; (c) $\mathrm{H}^{+}$reduction.

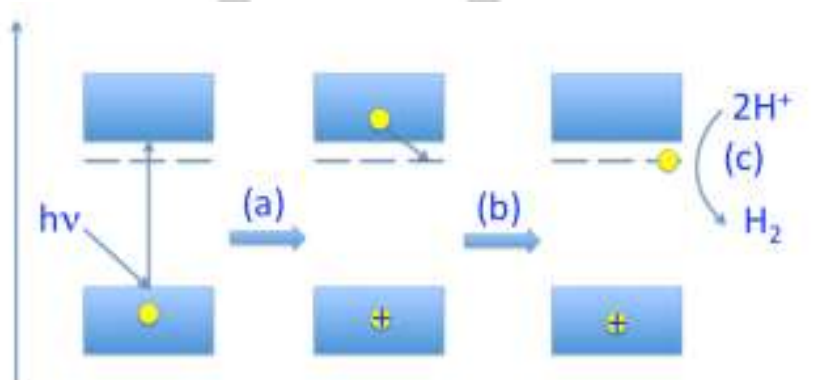

The above data refer to irradiations with simulated solar light that contains about $4 \%$ of the energy in the UV region and about $42 \%$ of the energy in the visible zone. Due to the lack of photocatalytic activity of titanium oxide under irradiation with visible light, there is a continuous interest in developing visible light photocatalysts.

In the present case, and considering that according to the absorption spectra the samples absorb light in the visible region, we were interested in determining if the doped FeP samples exhibit some photocatalytic activity with visible light. Aimed at addressing this issue we performed a set of photocatalytic tests using a $450 \mathrm{~nm}$ LED emitting light of wavelength above $420 \mathrm{~nm}$ (50 $\mathrm{mW} \times \mathrm{cm}^{-2}$ at a distance of $3 \mathrm{~cm}$, see emission spectra on supporting information). All the samples exhibit under this condition weak, but measurable photocatalytic activity. Figure 6 summarizes the hydrogen generation of $\mathrm{Cr}$-doped FeP samples under visible light. The results obtained indicate that under simulated sunlight a considerable proportion, about $66 \%$, of the photocatalytic activity is due to the UV light, despite that this wavelength zone corresponds to a minor percentage to the total solar energy.

Figure 6. Hydrogen production from water-methanol mixtures using (Cr)FeP as photocatalysts and visible-light LED as irradiation source. Reaction conditions: Water-methanol mixtures (1:1) $25 \mathrm{~mL}$, catalyst

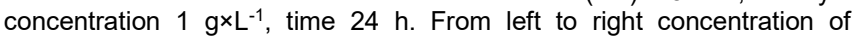
dopant element grows from: $0,0.25,0.5,1,2$ and $5 \%$.

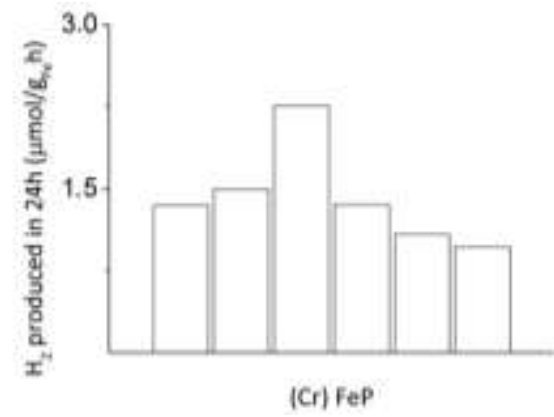


Estimation of the conduction band flat potential for FeP was carried out measuring the photocurrent against the bias potential, determining the value that change the photocurrent from positive to negative. These measurements give a flat band potential of $0.1 \mathrm{eV}$. Alternately, impedance spectroscopy of thin FeP films on transparent conductive electrode (see Figure S4 and S5) allowed also to determine the flat band potential and the density of charge carriers that was estimated based on this technique as $0.1 \mathrm{eV}$ and $2.6 \cdot 10^{20}$ carriers $/ \mathrm{cm}^{3}$.

The charge separation state, and its quenching behaviour as well as the influence of the metal doping were monitored by nanosecond transient absorption spectroscopy using $266 \mathrm{~nm}$ laser as excitation wavelength. In these experiments FeP samples were suspended in acetonitrile by sonication. After removal of the solid residues by decantation, the persistent FeP colloidal solutions were submitted to nanosecond laser flash excitation. Regardless the presence of dopant elements, all the transient spectra were characterized in the microsecond time scale by a continuous absorption spanning the whole wavelength range. As an example, Figure 7 shows the transient spectra for FeP reported at 1.9, 5.8 and $10.8 \mu$ s after the laser flash. The temporal profile of the signal monitored at different wavelengths was coincident, suggesting that it corresponds to the same transient. The temporal profile has three regimes (see Figure 7).

Figure 7. Transient Spectra recorded for $\mathrm{N}_{2}$-purged FeP suspended in acetonitrile (O.D. at $355 \mathrm{~nm} \mathrm{0.3)}$ ) at $0.26(\boldsymbol{\square}), 5.8(\mathbf{O})$ and $10.78(\mathbf{\Delta}) \mu \mathrm{s}$ after $355 \mathrm{~nm}$ laser excitation. Inset A: temporal profile of the transient spectrum monitored at $400 \mathrm{~nm}$. The profile shows three kinetic regimes that have been labelled as A, B and C, respectively. Inset B: temporal profile of the signal recorded for at $420 \mathrm{~nm}$ for suspension in acetonitrile (O.D. at $355 \mathrm{~nm} 0.31$ after $355 \mathrm{~nm}$ laser excitation (the plots $\mathrm{a}, \mathrm{b}$ and c corresponds to the temporal profiles after $\mathrm{N}_{2}$ and $\mathrm{O}_{2}$ purging or in presence of methanol, respectively).

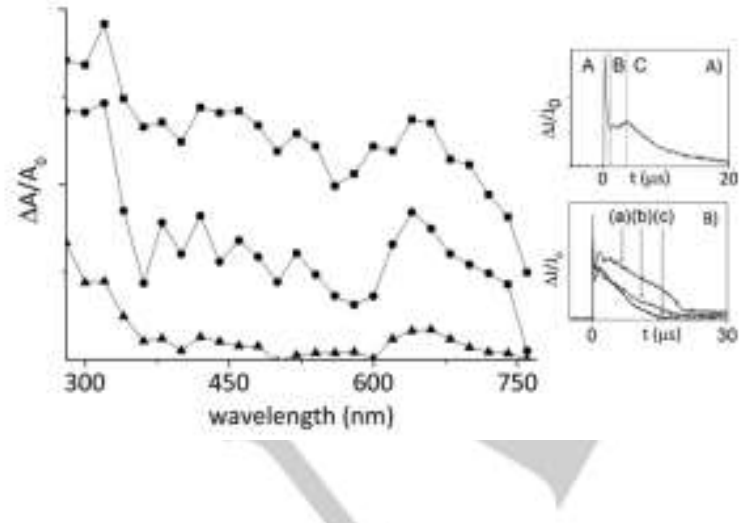

The first one is a fast decay, taking place in less than $0.15 \mu \mathrm{s}$ and corresponding to more than $60 \%$ of the top $\Delta \mathrm{J} / \mathrm{J}_{0}$. This fast decay is followed by a growth from 0.15 to about $2.0 \mu$ s that increases the $\Delta \mathrm{J} / \mathrm{J}_{0}$ signal about $10 \%$. The last kinetics correspond to the final decay of the signal that take place from 2.5 to $20 \mu \mathrm{s}$. As we will see below, quenching experiments support that this transient corresponds to the fraction of charge separated state of FeP materials decaying in the microsecond time scale. Then according this, the three kinetics could correspond to fast charge recombination (regime A), followed by charge migration and relocation into traps (regime $\mathrm{B}$ ) and final recombination of free charge carriers (regime $\mathrm{C}$ ).

No influence of the dopant elements either on the spectra or on temporal profiles was observed. However we notice that the intensity of the signal immediately after the laser pulse was dependent on the nature of dopant. This observation could suggest that the influence of the dopant element is more in disfavoring ultra fast charge recombination in the submicrosecond time scale of charge carriers than in the location or recombination kinetics at longer time scales since the latter will lead to changes in the transient spectra or in the transient signals. According to the proposal presented in Scheme 1, steps a and b should occur in time scales shorter than microseconds and this trapping will appear in the microsecond time scale as an increase in the intensity of initial density of charge separation.

Temporal profile of the signal was sensitive to the presence of quenchers (Figure 7). In the present study we use oxygen as conduction band electron quencher and methanol as valence band hole quencher. In the case of $\mathrm{FeP}$, the presence of oxygen increases the intensity of the signal corresponding to regimes $A$ and $C$ (Figure 7). Methanol increases more significantly the signal in region $C$ (Figure 7 ). This effect of the quencher increasing the intensity of the signal without affecting much to the kinetics of the decay can be interpreted considering that geminate charge recombination of electron and holes is the main decay pathway of the signal. If one quencher is present removing partially one of the charge carriers, then the transient signal can increase due to the detection of the complementary charge that has not collapsed by recombination and, therefore, reach the nanosecond time scale in larger concentrations. The influence of oxygen and methanol in the temporal profile of the signal is in agreement with assignment of the transient spectra to the combined absorption of electrons and holes. And the transient detected in the microsecond timescale being a fraction of the total charge separation events, specifically, the population of charge separated states that disappear in the sub microsecond time scale. As an example, Figure 7 shows the temporal profile of the signal monitored for FeP under argon or oxygen purging flow or in presence of methanol. Interestingly doped FeP follow the same general trend observed for undoped FeP. The most salient distinctive feature of $\mathrm{O}_{2} / \mathrm{CH}_{3} \mathrm{OH}$ quenching for doped FeP was that the influence of quenchers, particularly in the regime $C$ is considerably smaller than that presented in Figure 7 for FeP. Regardless the top $\Delta \mathrm{J} / \mathrm{J}_{0}$, at short delay times the signal for doped FeP was clearly influenced by the presence of the quenchers, but the signal decay at larger times was almost insensitive to the presence of $\mathrm{O}_{2}$ or $\mathrm{CH}_{3} \mathrm{OH}$ This could be due to the trapping charge carriers in the certain sites.

\section{Conclusions}

Overall the present results illustrate the potential of widely available $\mathrm{FeP}$ as photocatalyst for hydrogen production, combining advantages of photostability, higher reduction potential of conduction band electrons than $\square-\mathrm{Fe}_{2} \mathrm{O}_{3}$ and easy doping during the synthesis of the materials. Our results show that doping with metal elements can increase the photocatalytic activity of the FeP by a factor to 2.5 . 
The behaviour of FeP as semiconductor has been supported by photocurrent measurements and impedance spectroscopy that have allowed to establish the position of the conduction and valence band and an estimation of the density of carriers. The state of charge generation ahs been detected by transient absorption spectroscopy. It was found that the spectrum consist in a continuous absorption band spanning the whole wavelength range exhibiting three kinetic regimes and decaying completely in 20 microsecond. Assignment of the transient spectrum was based on the behaviour of the signal for oxygen and methanol that are typical electron and hole quencher, respectively.

Dopant elements influence the intensity of the transient signal that in this more intense due to the dopant also the interaction with quenchers that makes the materials less sensitive to quenchers.

Thus, the present findings can open the way for further development of a novel family of semiconductors with promising applications as photocatalysts that are based on affordable elements iron and phosphor.

\section{Experimental Section}

Materials preparation: One-dimensional iron phosphate (FeP) was prepared as reported from Song ${ }^{[31]}$, ${ }^{[32]}$. Briefly, an aqueous solution of ferric chloride, phosphoric acid and ethylendiamine $\left(\mathrm{FeCl}_{3} 0.005\right.$ mol: $\mathrm{H}_{3} \mathrm{PO}_{4} 0.04 \mathrm{~mol}: \mathrm{NH}_{2} \mathrm{CH}_{2} \mathrm{CH}_{2} \mathrm{NH}_{2} 2.5 \mathrm{~mL}: \mathrm{H}_{2} \mathrm{O} 35 \mathrm{~mL}$ ) was placed into a Teflon-lined autoclave of $200 \mathrm{~mL}$, using a filling factor of $75 \%$. The autoclave was heated at $150{ }^{\circ} \mathrm{C}$ during $2.5 \mathrm{~h}$ and after this time the reaction mixture was cooled at room temperature using an ice bath. The precipitate was filtered, washed and dried in vacuum at room temperature. The doped materials were prepared following the same synthetic protocol using a mixture of ferric chloride and chromium, manganese or cobalt chloride in proportions ranging from of $0.25-5 \mathrm{wt} \%$ as dopant.

Photocatalytic tests for hydrogen production: A suspension of the catalyst $\left(25 \mathrm{~mL}, 1 \mathrm{~g} \times \mathrm{L}^{-1}\right)$ was sonicated for $10 \mathrm{~min}$ and placed in a closed reactor with an irradiation window of $12.56 \mathrm{~cm}^{2}$ provided with temperature and pressure controllers. The reactor was placed in a thermostatic bath with a set point temperature of $25{ }^{\circ} \mathrm{C}$. The suspension was purged with an argon flow of $2 \mathrm{psi}$ for $15 \mathrm{~min}$ prior to irradiation. The photoreaction was performed from the top of the photoreactor by using a visible light LED or a solar simulator (Thermo Oriel $1000 \mathrm{~W}$ ) with an irradiation spot of $100 \mathrm{~cm}^{2}$ placed at a distance of $10 \mathrm{~cm}$. The light of the solar simulator was filtered through an Air Mass 1.5 filter and contains approximately $4 \%$ of UV light. The amount of hydrogen collected in the headspace of the reactor was analysed by injecting $100 \mu \mathrm{L}$ in a gas chromatograph using a MOLSieve column, argon as carrier gas and a TC detector. Photocurrent measurements and determination of flat band potential of the conduction band: For photocurrent measurements, thin films of $\mathrm{FeP}$ were deposited on an FTO electrode ("Solaronix" $0.8 \times 10$ $\mathrm{cm}^{2}$ ). Deposition was performed by spreading a paste containing the semiconductor on the FTO surface using the doctor blade procedure. The surface of FTO was defined by adhesive tape. The paste containing the semiconductor was prepared in advance to the deposition of the film onto the electrode by dispersing $100 \mathrm{mg}$ of $\mathrm{FeP}$ $1 \mathrm{ml}$ of acetone and $1 \mathrm{ml}$ of $\alpha$-tert-pineol. The suspension was stirred for $24 \mathrm{~h}$ to achieve a homogeneous dispersion. Then, acetone and $\alpha$-terpineol were allowed to evaporate a room temperature to obtain the final dense semiconducting paste. After deposition of the paste, the adhesive tape was removed and the film of semiconductor on FTO was submitted to heating at $80^{\circ} \mathrm{C}$ for $24 \mathrm{~h}$ hour to increases the mechanical resistance of the layer. Photocurrent measurements were carried out using a $150 \mathrm{~W}$ Xenon arc lamp as a light source and a PTI model 101 monochromator. Electrical current was measured with an Amel 7050 potentiostat that was connected electrically to the FTO electrode with a platinum wire as counter electrode. The experiments were conducted inside a quartz cuvette $(20 \mathrm{ml})$ that contained an aqueous $0.1 \mathrm{M} \mathrm{KCl}$ solution as electrolyte. The system was purged with nitrogen for at least 15 min before the measurement. Flat conduction band potential was determined by measurements of photocurrent applying increasing bias from 0.3 to $-0.3 \mathrm{Vs}$ (ref. $\mathrm{Ag} / \mathrm{AgCl}$ ) every $0.1 \mathrm{~V}$ ( 7 points). Photocurrent onset was detected at $365 \mathrm{~nm}$ and the scan rate was of $2 \mathrm{~min}$ to stabilize, one of them without irradiation and the next min illuminating the cell.

The number of charge carriers was determined using the same system connected to a frequency response analyser. The experiment was carried from $0.5 \mathrm{~V}$ to $-0.1 \mathrm{~V}$ each $0.1 \mathrm{~V}$ ( 7 points). At each voltage the system scanned in the frequency from $105 \mathrm{~Hz}$ from $0.1 \mathrm{~Hz}$.

Transient absorption spectroscopy: Suspensions of FeP or doped FeP in acetonitrile were prepared by sonicating the powder for 10 min at $150 \mathrm{~W}$. The amount of solid was set to obtain an optical density at 266 of 0.35 units. The suspensions were persistent during the time needed for the transient absorption spectra measurements (about $3 \mathrm{~h}$ ) without deposition of any solid $3 \mathrm{ml}$ of these acetonitrile suspensions were placed in a Suprasil quartz cuvette of $1 \times 1 \mathrm{~cm}^{2}$ capped with septa. Suspensions were purged with argon or oxygen (for quenching experiments) for at least $15 \mathrm{~min}$ before the measurements. For ethanol quenching, an argon flow was bubbled through the suspension of $\mathrm{FeP}$ for at least $50 \mathrm{~min}$ before measurements. Transient measurements were carried out using the fourth (266 nm, $20 \mathrm{~mJ} /$ pulse) harmonic of a Nd:YAG laser $(7 \mathrm{~ns}$ fwhp) as excitation source. The transient signal was recorded by transmission mode using a $150 \mathrm{~W}$ xenon lamp as monitoring beam through fiber optics to collect the transmitted light.The signal from the monochromator/photomultiplier detection system was captured by a Tektronix 2440 digitizer and transferred to a PC computer that controlled the experiment and provided suitable processing and data storage capabilities.

Keywords: photocatalysis, hydrogen production, iron hydroxyl phosphate as semiconductor

\section{Acknowledgements}

Financial support by the Spanish Ministry of Economy and Competitiveness (Severo Ochoa and CTQ20212-32315) and Generalidad Valenciana (Prometeo 2012/014) is gratefully acknowledged. M.S. thank the Spanish CSIC and Technical University of Valencia for a postgraduate scholarship.

[a] Dr. M. Serra, Mr. H. G. Baldoví, Prof. M. Alvaro and Prof. Hermenegildo Garcia

Instittuto Universitario de Tecnologia Quimica, Universidad Politécnica de Valencia, Avenida de los Naranjos S/N, 46022 Valencia, Spain E-mail: hgarcia@qim.upv.es

Supporting information for this article is given via a link at the end of the document. 


\section{References}

[1] Y. Amao, Chemcatchem 3 (2011) 458

[2] G. Centi, S. Perathoner, ChemSusChem 3 (2010) 195

[3] D. Gust, T. A. Moore, A. L. Moore, Accounts of Chemical Research 42 (2009) 1890

[4] L. Hammarstrolı̀m, S. Hammes-Schiffer, Accounts of Chemical Research 42 (2009) 1859.

[5] N. Serpone, D. Lawless, R. Terzian, Solar Energy 49 (1992), 221

[6] D. Abbott, Proceedings of the leee 98 (2010) 42.

[7] S. Dunn, International Journal of Hydrogen Energy 27 (2002) 235

[8] P. V. Kamat, Journal of Physical Chemistry C 111 (2007) 2834.

[9] N. S. Lewis, D. G. Nocera, Proceedings of the National Academy of Sciences 103 (2006) 15729.

[10] A. J. Bard, M. A. Fox, Accounts of Chemical Research 28 (1995) 141.

[11] S. Bensaid, G. Centi, E. Garrone, S. Perathoner, G. Saracco, ChemSusChem 5 (2012) 500

[12] X. Chen, S. Shen, L. Guo, S. S. Mao, Chemical Reviews 110 (2010), 6503.

[13] G. W. Crabtree, M. S. Dresselhaus, M. V. Buchanan, Physics Today 57 (2004) 39.

[14] M. Gratzel, Accounts of Chemical Research 14 (1981) 376.

[15] M. Ni, M. K. H. Leung, D. Y. C. Leung, K. Sumathy, Renewable and Sustainable Energy Reviews 11 (2007) 401.

[16] J. Nowotny, C. C. Sorrell, L. R. Sheppard, T. Bak, International Journal of Hydrogen Energy 30 (2005) 521.

[17] D. W. Bahnemann, Research on Chemical Intermediates 26 (2000) 207

[18] M. A. Fox, M. T. Dulay, Chemical Reviews 93 (1993) 341

[19] A. Fujishima, X. Zhang, D. A. Tryk, Surf. Sci. Rep. 63 (2008) 515

[20] J. M. Herrmann, Catalysis Today 53 (1999)115.

[21] A. L. Linsebigler, G. Q. Lu, J. T. Yates, Chemical Reviews 95 (1995) 735

[22] A. Mills, S. LeHunte, Journal of Photochemistry and Photobiology aChemistry 108 (1997) 1.

[23] N. Beermann, L. Vayssieres, S. E. Lindquist, A. Hagfeldt, Journal of the Electrochemical Society 147 (2000) 2456.

[24] U. Bjorksten, J. Moser, M. Gratzel, Chemistry of Materials 6 (1994) 858.

[25] Y.-S. Hu, A. Kleiman-Shwarsctein, A. J. Forman, D. Hazen, J.-N. Park, E. W. McFarland, Chemistry of Materials 20 (2008) 3803

[26] A. Kay, I. Cesar, M. Graetzel, Journal of the American Chemical Society 128 (2006) 15714.

[27] K. Sivula, F. Le Formal, M. Graetzel, ChemSusChem 4 (2011) 432

[28] K. Sivula, R. Zboril, F. Le Formal, R. Robert, A. Weidenkaff, J. Tucek, J. Frydrych, M. Graetzel, Journal of the American Chemical Society 132 (2010) 7436

[29] M. Gratzel, Nature (London, U. K.) 414 (2001) 338

[30] X. J. Wang, H. Pang, S. Zhao, W. Shao, B. Yan, X. Li, S. Li, J. Chen, W. Du, ChemPhysChem 14 (2013) 2518

[31] Y. Song, P. Y. Zavalij, N. A. Chernova, M. Suzuki, M. S. Whittingham, Journal of Solid State Chemistry 175 (2003) 63.

[32] Y. Song, P. Y. Zavalii, N. A. Chernova, M. S. Whittingham, Chemistry of Materials 17 (2005) 1139 


\section{FULL PAPER}

Text for Table of Contents

Open framework iron hydroxyl phosphate can be easily doped and exhibits semiconductor behaviour under visible light for hydrogen generation

\section{Photocatalysis}

Marco Serra, Herme G.

Baldovi, Mercedes Alvaro and Hermenegildo Garcia*

Page No. - Page No.

Doped framework iron hydroxyl phosphate as novel photocatalyst for hydrogen production from water-methanol mixtures 